\title{
Assessment of Nurses' knowledge and Practices related to Infection Control of Invasive Procedures in Neonatal Units at EL-Minia University and General Hospitals
}

\author{
Abolwafa , N., F; Ouda , W., Els; Mohammed , F., Z \& Masoed , E., Sayed. \\ Pediatric Nursing Department, Faculty of Nursing, Minia University, Egypt \\ Pediatric Nursing Department, Faculty of Nursing, Ain Shams University Egypt \\ Pediatric Nursing Department, Faculty of Nursing, Assiut University, Egypt
}

\begin{abstract}
All neonates at the neonatal units are routinely subjected to invasive procedures. Where nearly, all of them are attached to various types of invasive procedures. So infection control in a health care facility can reduce the risk of nosocomial infections, thus decreases morbidity and mortality rates, cost and burden on families, hospitals and the community as well. Aim of the study was to assess the nurses' knowledge and practices about infection control of invasive procedure in the neonatal units. This study is a descriptive study, that was conducted in the neonatal units at El-Minia University and General Hospitals. The study sample: was a convenient sample of 40 nurses (22 nurses from El-Minia University and 18 nurses from El-Minia General Hospitals). The following tools were used: 1) A structured questionnaire sheet, 2) Observation checklist sheet. Results of the study showed that half percentage of nurses' satisfactory knowledge was related to infection (50\%) followed by universal precaution (35\%). The satisfactory knowledge of nurses was related to suctioning $(65 \%)$ followed by nasogastric tube insertion $(55 \%)$. The total knowledge about infection control and invasive procedure were satisfactory in $25 \%$ of them. Conclusion nurse were lacking knowledge and practices related to infection control of invasive procedures. Recommendations a Provision of continuing education programs on regular basis is suggested in order to refresh and update nurse's knowledge, as well as reinforce proper practice related to infection control of invasive procedure in neonatal intensive care unit.
\end{abstract}

Keywords: Infection Control, Invasive Procedures, NICU, pediatric, nursing

\section{Introduction}

The Neonatal Intensive Care Unit (NICU) is the unit that provides specialized care that is critical to sustain and nurture new life. Infants who have complications due to premature birth, infections or other health challenges are admitted to this unit (Wikimedia Foundation, 2006). Neonates who are colonized with pathogens may have no overt signs of illness. Overcrowding and understaffing of the unit, inadequate number of sinks, or their poor accessibility may contribute to decreased hand washing. Invasive procedures increase the risk of infection due to the interruption of the normal barriers. Examples of such procedures are the use of fetal scalp electrodes, heel sticks, nasogastric tubes, endotracheal tubes and intravascular lines. Prevention of infections requires meticulous neonatal care techniques and careful attention to all aspects of infection control (Milligan, et al., 2011).

The rate of nosocomial infections in neonatal intensive care units (NICUs) has been reported at 6 to $25 \%$ with the highest involvement in the invasive procedure (Mary, 2005)

Good health depends on safe environment, which is free from any hazards. Neonate's, in all health care settings are at risk for acquiring infection (Potter and
Perry, 2004). Infection is defined as invasion of the body by pathogens or microorganism capable of producing diseases (White Lois, 2007). Nosocomial infection is one that is acquired while hospitalized that is not present at admission (Terri and Kyle, 2008).

Invasive procedure can be defined as medical procedure that invades (enters) the body, usually by cutting or puncturing the skin or by inserting instruments into the body. Invasive Procedures are punctures of the skin or insertion of an instrument into the body of the neonates (National Institutes of Health, 2009). For example: inserting endotracheal tube, suctioning, umbilical vessel catheterization, intravenous line placement, capillary blood sampling and venipuncture and nasogastric tube (Chemaly, 2007).

In many NICUs today, qualified registered nurses perform many invasive procedure rather than physicians. Prior to performing any invasive procedure it is essential that one must have knowledge of the indications, precautions and complications associated with each procedure. Neonates are extremely vulnerable; therefore, the ability to perform the procedure proficiently is a major requirement to prevent harm (Terese and 
Markene, 2010). Prevention of infection requires meticulous neonatal care techniques and careful attention to all aspects of infection control (Milligan, et al., 2011).

\section{Subjects and Methods}

The aim of this study was to: Assess the nurses' knowledge and practices about infection control of invasive procedure in the neonatal units.

\section{Research Questions:}

1. Is there a relationship between the studied nurses' personal characteristics and their knowledge and practices about infection control of invasive procedure?

2. Is there a relationship between the studied nurses' knowledge and practices?

Research design: Descriptive research design was utilized to meet the aim of this study

Setting: This study was conducted in neonatal units at El-Minia University and General Hospitals.

Sampling: A convenient sample of 40 nurses (22 nurses from El-Minia University and 18 nurses General Hospitals) regardless their characteristics.

\section{Tools for Data Collection:}

Tool I: A structured questionnaire sheet for nurses that was designed by the researcher in an Arabic language after reviewing of the related literature to assess the nurses' knowledge towards infection control of invasive procedures in neonatal units. It comprised the following parts:-

\begin{tabular}{|c|c|}
\hline Part1 & $\begin{array}{l}\text { Personal data: as nurses' age, } \\
\text { qualifications, years of experience and } \\
\text { previous training courses. }\end{array}$ \\
\hline Part $_{2}$ & $\begin{array}{l}\text { Nurses' knowledge towards infection } \\
\text { control of invasive procedures in } \\
\text { neonatal units. Close ended questions } \\
\text { were used that involve } 66 \text { items divided } \\
\text { to } 37 \text { items (knowledge about infection } \\
\text { control) and } 29 \text { items (invasive } \\
\text { procedures). }\end{array}$ \\
\hline
\end{tabular}

Tool II: Observation checklists sheet that were adopted from Terese and Marlene, (2010); Patricia and Anne, (2005) to assess the nurses' practices about infection control of invasive procedure namely Universal precautions including: hand washing, gloving, masking, gowning and Invasive procedures including: nursing care before, during and after intubation of endotracheal tube, suctioning, nursing care before, during and after insertion of; an umbilical vessel catheterization, peripheral intravenous line, capillary blood sampling, venipuncture and nasogastric tube.

Administrative approval was obtained from the Dean of Faculty of Nursing, El-Minia University to the head manger of El-Minia University and General Hospital and the head of the neonatal units before implementation of the study.

Pilot study

After developing the tools, a pilot study was conducted on 5 nurses in El-Minia University Hospital and 5 nurses in El-Minia General Hospital. To test clarity \& applicability of the study tools and to determine the time required to fill each tool. According to the results of pilot, the needed modification (omissions and/or additions) were done. A jury acceptance of the final forms was secured before actual study work and the reliability was assessed in a pilot study by measuring their internal consistency using Cronbach's alpha coefficient method.

\section{Ethical consideration:}

The oral consent was taken from all nurses participating in the study and parents of the neonates. The researcher explained purpose of the study through direct personal communication. They were secured that data will be confidential and will be used for the research purpose only.

\section{Scoring system:}

Scoring system: Nurses' knowledge: a score of one was given for correct answer and a zero for incorrect answer. For each part, the scores of the items were summed up and the total divided by number of the items, giving a mean score for the part. The nurses' knowledge was considered satisfactory if the percent score is $60 \%$ or more and unsatisfactory if scored less than $60 \%$.

Nurses' practice: a score of 2 was given for done correctly; score of 1 was given for done incorrectly. For each part, the scores of the items were summed up and the total divided by number of the items, giving a mean score for the area. These scores were converted into a percent score and mean and standard deviations were computed. The nurses' practice was considered satisfactory if the percent score is $60 \%$ or more and unsatisfactory if scored less than $60 \%$.

\section{Statistical analysis:}

Data entry was done using compatible personal computer. The statistical - analysis was done using SPSS-13 statistical software package and Excel for figures. The content of each tool was coded, categorized and then analyzed. Data were presented using descriptive statistics in the form of frequencies and percentages for qualitative variables and means and standard deviations for quantitative variables. The qualitative studied variables were compared using Chi-square test. Statistical significance used at $P$. value $<0.05$. 


\section{Results:}

Table (1): Distribution of nurses according to their characteristics $n=40$

\begin{tabular}{|c|c|c|}
\hline Items & No & $\%$ \\
\hline $\begin{array}{l}\text { Age in years: } \\
<20 \\
20<30 \\
30<40\end{array}$ & $\begin{array}{c}6 \\
28 \\
6 \\
\end{array}$ & $\begin{array}{l}15 \\
70 \\
15 \\
\end{array}$ \\
\hline${ }^{-} x \pm S D$ & \multicolumn{2}{|c|}{$1.95 \pm 0.27$} \\
\hline $\begin{array}{l}\text { Qualification of nurses: } \\
\text { Bachelor in Nursing Sciences } \\
\text { Diplom of Technical Nursing Institute } \\
\text { Diplom of Secondary Nursing School } \\
\end{array}$ & $\begin{array}{c}10 \\
7 \\
23 \\
\end{array}$ & $\begin{array}{c}25 \\
17.5 \\
57.5\end{array}$ \\
\hline $\begin{array}{l}\text { Years of experience: } \\
\quad<5 \\
\quad 5<10 \\
10<15\end{array}$ & $\begin{array}{c}8 \\
26 \\
6 \\
\end{array}$ & $\begin{array}{l}20 \\
65 \\
15 \\
\end{array}$ \\
\hline${ }^{-} \mathrm{x} \pm \mathrm{SD}$ & \multicolumn{2}{|c|}{$1.70 \pm 0.59$} \\
\hline $\begin{array}{l}\text { Previous attendance of training courses about infection } \\
\text { control of invasive procedure: } \\
\text { Yes } \\
\text { No }\end{array}$ & $\begin{array}{c}4 \\
36\end{array}$ & $\begin{array}{l}10 \\
90\end{array}$ \\
\hline $\begin{array}{l}\text { Neonatal unit affiliated to: } \\
\text { El-Minia University Hospital (MUH) } \\
\text { El-Minia General Hospital (MGH) }\end{array}$ & $\begin{array}{l}22 \\
18\end{array}$ & $\begin{array}{l}55 \\
45\end{array}$ \\
\hline
\end{tabular}

Table (2): The relation between the studied sample knowledge about infection control and their personal characteristics $n=40$

\begin{tabular}{|c|c|c|c|c|c|c|}
\hline \multirow{3}{*}{ Items } & \multicolumn{4}{|c|}{ Knowledge } & \multirow{3}{*}{$\mathbf{X}^{2}$} & \multirow{3}{*}{ P. value } \\
\hline & \multicolumn{2}{|c|}{ Satisfactory } & \multicolumn{2}{|c|}{ Unsatisfactory } & & \\
\hline & No & $\%$ & No & $\%$ & & \\
\hline \multicolumn{5}{|l|}{ Age in years: } & \multirow{4}{*}{0.98} & \multirow{4}{*}{$0.02 *$} \\
\hline$<20$ & 5 & 12.5 & 1 & 2.5 & & \\
\hline $20<30$ & 9 & 22.5 & 19 & 47.5 & & \\
\hline $30<40$ & 0 & 0 & 6 & 15 & & \\
\hline \multicolumn{5}{|l|}{ Years of experience: } & \multirow{4}{*}{0.71} & \multirow{4}{*}{$0.01 *$} \\
\hline$<5$ & 3 & 7.5 & 5 & 12.5 & & \\
\hline $5<10$ & 19 & 47.5 & 7 & 17.5 & & \\
\hline $10<15$ & 0 & 0 & 6 & 15 & & \\
\hline \multicolumn{5}{|l|}{ Qualification of nurses: } & \multirow{4}{*}{0.45} & \multirow{4}{*}{$0.04 *$} \\
\hline Bachelor in Nursing Sciences & 8 & 20 & 2 & 5 & & \\
\hline Diploma of Technical Nursing Institute & 3 & 7.5 & 4 & 10 & & \\
\hline Diploma of Secondary Nursing School & 5 & 12.5 & 18 & 45 & & \\
\hline \multicolumn{5}{|l|}{ Previous attendance of training courses: } & \multirow{3}{*}{0.48} & \multirow{3}{*}{0.34} \\
\hline Yes & 2 & 5 & 2 & 5 & & \\
\hline No & 8 & 20 & 28 & 70 & & \\
\hline
\end{tabular}


Table (3): The relation between the studied sample knowledge about invasive procedures and their personal characteristics $n=40$

\begin{tabular}{|c|c|c|c|c|c|c|}
\hline \multirow{3}{*}{ Items } & \multicolumn{4}{|c|}{ Knowledge } & & \multirow{3}{*}{ P. value } \\
\hline & \multicolumn{2}{|c|}{ Satisfactory } & \multicolumn{2}{|c|}{ Unsatisfactory } & & \\
\hline & No & $\%$ & No & $\%$ & & \\
\hline \multicolumn{5}{|l|}{ Age in years: } & \multirow{4}{*}{0.65} & \multirow{4}{*}{$0.001 *$} \\
\hline$<20$ & 0 & 0 & 6 & 15 & & \\
\hline $20<30$ & 23 & 57.5 & 5 & 12.5 & & \\
\hline $30<40$ & 5 & 12.5 & 1 & 2.5 & & \\
\hline \multicolumn{5}{|l|}{ Years of experience: } & \multirow{4}{*}{0.27} & \multirow{4}{*}{$0.01 *$} \\
\hline$<5$ & 0 & 0 & 8 & 20 & & \\
\hline $5<10$ & 6 & 15 & 20 & 50 & & \\
\hline $10<15$ & 4 & 10 & 2 & 5 & & \\
\hline \multicolumn{5}{|l|}{ Qualification of nurses: } & \multirow{4}{*}{0.061} & \multirow{4}{*}{$0.001 *$} \\
\hline Bachelor in Nursing Sciences & 1 & 2.5 & 9 & 22.5 & & \\
\hline Diploma of Technical Nursing Institute & 2 & 5 & 5 & 12.5 & & \\
\hline Diploma of Secondary Nursing School & 16 & 40 & 7 & 17.5 & & \\
\hline \multicolumn{5}{|l|}{ Previous attendance of training courses: } & \multirow{3}{*}{0.40} & \multirow{3}{*}{0.55} \\
\hline Yes & 3 & 7.5 & 1 & 2.5 & & \\
\hline No & 9 & 22.5 & 27 & 67.5 & & \\
\hline
\end{tabular}

Table (4): Nurses' knowledge related to infection control. $n=40$

\begin{tabular}{|l|c|c|c|c|}
\hline \multirow{2}{*}{ Items } & \multicolumn{2}{c|}{ Satisfactory (> 60\%) } & \multicolumn{2}{c|}{ Unsatisfactory (<60\%) } \\
\cline { 2 - 5 } & No & $\%$ & No & \% \\
\hline Infection. & 20 & 50 & 20 & 50 \\
\hline Cleaning and disinfection. & 4 & 10 & 36 & 90 \\
\hline Sterilization. & 8 & 20 & 32 & 80 \\
\hline Universal precaution. & 14 & 35 & 26 & 65 \\
\hline Total of nurses' knowledge about infection control. & 10 & 25 & 30 & 75 \\
\hline
\end{tabular}

Table (5): Nurses' knowledge related to invasive procedures. $n=40$

\begin{tabular}{|l|c|c|c|c|}
\hline \multicolumn{2}{|c|}{ Items } & \multicolumn{2}{c|}{ Satisfactory (> 60\%) } & \multicolumn{2}{c|}{ Unsatisfactory (< 60\%) } \\
\cline { 2 - 5 } & No & $\mathbf{\%}$ & No & \% \\
\hline Invasive procedures & 6 & 15 & 34 & 85 \\
\hline Endotracheal (ET) intubation & 12 & 30 & 28 & 70 \\
\hline Suctioning & 26 & 65 & 14 & 35 \\
\hline Umbilical vessel catheterization & 8 & 20 & 32 & 80 \\
\hline Peripheral intravenous line placement & 12 & 30 & 28 & 70 \\
\hline Blood Sampling & 14 & 35 & 26 & 65 \\
\hline Nasogastric tube insertion & 22 & 55 & 18 & 45 \\
\hline Total nurses' knowledge about invasive procedures & 10 & 25 & 30 & 75 \\
\hline
\end{tabular}


Table (6): The relation between the studied sample practice about infection control and their personal characteristics $n=40$

\begin{tabular}{|c|c|c|c|c|c|c|}
\hline \multirow{3}{*}{ Items } & \multicolumn{4}{|c|}{ Practice } & \multirow{3}{*}{$\mathbf{X}^{2}$} & \multirow{3}{*}{ P. value } \\
\hline & \multicolumn{2}{|c|}{ Satisfactory } & \multicolumn{2}{|c|}{ Unsatisfactory } & & \\
\hline & No & $\%$ & No & $\%$ & & \\
\hline \multicolumn{5}{|l|}{ Age in years: } & \multirow{4}{*}{0.60} & \multirow{4}{*}{0.74} \\
\hline$<20$ & 2 & 5 & 4 & 10 & & \\
\hline $20<30$ & 14 & 35 & 14 & 35 & & \\
\hline $30<40$ & 1 & 2.5 & 5 & 12.5 & & \\
\hline \multicolumn{5}{|l|}{ Years of experience: } & \multirow{4}{*}{0.34} & \multirow{4}{*}{0.93} \\
\hline$<5$ & 2 & 5 & 6 & 15 & & \\
\hline $5<10$ & 8 & 20 & 18 & 45 & & \\
\hline $10<15$ & 2 & 5 & 4 & 10 & & \\
\hline \multicolumn{5}{|l|}{ Qualification of nurses: } & \multirow{4}{*}{0.71} & \multirow{4}{*}{$0.05^{*}$} \\
\hline Bachelor in Nursing Sciences & 4 & 10 & 6 & 15 & & \\
\hline Diploma of Technical Nursing Institute & 3 & 7.5 & 4 & 10 & & \\
\hline Diploma of Secondary Nursing School & 10 & 25 & 13 & 32.5 & & \\
\hline \multicolumn{5}{|l|}{ Previous attendance of training courses: } & \multirow{3}{*}{0.53} & \multirow{3}{*}{0.25} \\
\hline Yes & 3 & 7.5 & 1 & 2.5 & & \\
\hline No & 11 & 27.5 & 25 & 62.5 & & \\
\hline
\end{tabular}

Table (7): The relation between the studied sample practice about invasive procedures and their personal characteristics $\mathrm{n}=\mathbf{4 0}$

\begin{tabular}{|c|c|c|c|c|c|c|}
\hline \multirow{3}{*}{ Items } & \multicolumn{4}{|c|}{ Practice } & \multirow{3}{*}{$\mathbf{X}^{2}$} & \multirow{3}{*}{ P. value } \\
\hline & \multicolumn{2}{|c|}{ Satisfactory } & \multicolumn{2}{|c|}{ Unsatisfactory } & & \\
\hline & No & $\%$ & No & $\%$ & & \\
\hline \multicolumn{5}{|l|}{ Age in years: } & \multirow{4}{*}{0.65} & \multirow{4}{*}{0.25} \\
\hline$<20$ & 0 & 0 & 6 & 15 & & \\
\hline $20<30$ & 4 & 10 & 24 & 60 & & \\
\hline $30<40$ & 2 & 5 & 4 & 10 & & \\
\hline \multicolumn{5}{|l|}{ Years of experience: } & \multirow{4}{*}{0.90} & \multirow{4}{*}{0.54} \\
\hline$<5$ & 3 & 7.5 & 5 & 12.5 & & \\
\hline $5<10$ & 5 & 12.5 & 21 & 52.5 & & \\
\hline $10<15$ & 0 & 0 & 6 & 15 & & \\
\hline \multicolumn{5}{|l|}{ Qualification of nurses: } & \multirow{4}{*}{0.76} & \multirow{4}{*}{$0.05^{*}$} \\
\hline Bachelor in Nursing Sciences & 3 & 7.5 & 7 & 17.5 & & \\
\hline Diploma of Technical Nursing Institute & 2 & 5 & 5 & 12.5 & & \\
\hline Diploma of Secondary Nursing School & 9 & 22.5 & 14 & 35 & & \\
\hline \multicolumn{5}{|l|}{ Previous attendance of training courses: } & \multirow{3}{*}{0.78} & \multirow{3}{*}{0.22} \\
\hline Yes & 4 & 10 & 0 & 0 & & \\
\hline No & 6 & 15 & 30 & 75 & & \\
\hline
\end{tabular}

Table (8): Nurses' practice related to infection control. $n=40$

\begin{tabular}{|l|c|c|c|c|}
\hline \multirow{2}{*}{\multicolumn{2}{c|}{ Items }} & \multicolumn{2}{c|}{ Satisfactory(> 60\%) } & \multicolumn{2}{c|}{ Unsatisfactory(<60\%) } \\
\cline { 2 - 5 } & $\mathbf{N o}$ & $\mathbf{\%}$ & No & $\mathbf{\%}$ \\
\hline Hand washing. & 12 & 30 & 28 & 70 \\
\hline Gloving. & 6 & 15 & 34 & 85 \\
\hline Masking. & 4 & 10 & 36 & 90 \\
\hline Gowning. & 4 & 10 & 36 & 90 \\
\hline Total scores of universal precautions practice & 12 & 30 & 28 & 70 \\
\hline
\end{tabular}


Table (9): Nurses' practices related to invasive procedures. $n=40$

\begin{tabular}{|c|c|c|c|c|}
\hline \multirow[t]{2}{*}{ Items } & \multicolumn{2}{|c|}{$\begin{array}{l}\text { Satisfactory } \\
(>60 \%)\end{array}$} & \multicolumn{2}{|c|}{$\begin{array}{c}\text { Unsatisfactory } \\
(<60 \%)\end{array}$} \\
\hline & No & $\%$ & No & $\%$ \\
\hline Nursing care before intubation of endotracheal tube & 16 & 40 & 24 & 60 \\
\hline Nursing care during intubation of endotracheal tube & 14 & 35 & 26 & 65 \\
\hline Nursing care after intubation of endotracheal tube & 10 & 25 & 30 & 75 \\
\hline Total score of intubation of endotracheal tube & 8 & 20 & 32 & 80 \\
\hline Suctioning & 18 & 45 & 22 & 55 \\
\hline Nursing care before insertion of umbilical vessel catheterization & 20 & 50 & 20 & 50 \\
\hline Nursing care during insertion of umbilical vessel catheterization & 6 & 15 & 34 & 85 \\
\hline Nursing care after insertion of umbilical vessel catheterization & 18 & 45 & 22 & 55 \\
\hline Total score insertion of umbilical vessel catheterization & 4 & 10 & 36 & 90 \\
\hline Peripheral intravenous line placement & 12 & 30 & 28 & 70 \\
\hline Capillary blood sampling & 4 & 10 & 36 & 90 \\
\hline Venipuncture (phlebtomy) & 12 & 30 & 28 & 70 \\
\hline Nasogastric tube & 14 & 35 & 26 & 65 \\
\hline Total score of invasive procedure & 6 & 15 & 34 & 85 \\
\hline
\end{tabular}

Table (1) As regards the Personal characteristics of the studied sample it was found that more than two thirds $(70 \%)$ of them were aged $20<30$ years, with a mean age \& SD $1.70 \pm 0.59$ years. As regards nurses' marital status it was clear that, more than three quadrants of nurses' (85\%) were married. As regards qualification of studied sample it was found that, more than half of them were having Diplom of Secondary Nursing school (57.5\%). As for the nurses' years of experience, it was noticed that about two thirds of them $(65 \%)$ were having work experience that ranged from $5<10$ years, while $15 \%$ of them were having work experience ranged from $10<15$ years, with a mean \& SD $1.70 \pm 0.59$ years. Regarding to the previous attendance of training courses about infection control of invasive procedures, the majority of the studied sample $(90 \%)$ didn't have training courses about infection control of invasive procedures. Regarding to the place of work, it was found that $55 \%$ of the nurses were working at El- Minia University Hospital (MUH) and 45\% from El- Minia General Hospital (MGH).

Table (2) illustrates the relation between the studied sample knowledge about infection control and their personal characteristics. It is evident that there is statistically significant relation between nurses' age $(\mathrm{P}=0.02), \quad$ years of experience (P. 0.01), qualification and their knowledge $(\mathrm{P}=0.04)$. It is evident that higher percentages of satisfactory knowledge were observed among nurses younger than 20 years old $(12.5 \%)$, about half of the nurses with years of experience from 5 years to 10 years or more $(47.5 \%)$ had satisfactory knowledge, compared to only $7.5 \%$ of those with less than 5 years experience. Meanwhile, the table shows no statistically significant difference between nurses' knowledge and their previous attendance of training courses $(\mathrm{P}=>0.05)$.

Table (3) shows the relation between the studied sample knowledge about invasive procedures and their personal characteristics. It is evident that statistically significant relation between the nurses' age $(\mathrm{P}=0.001)$, years of experience $(\mathrm{P}=0.01)$ qualification and their knowledge $(\mathrm{P}=0.001)$. It is evident that higher percentages of satisfactory knowledge were observed among nurses age from 20 years old to 30 years or more $(57.5 \%)$, the nurses with years of experience from 5 years to 10 years or more $(15 \%)$ had satisfactory knowledge, compared to only $7.5 \%$ of those with less than 5 years experience and nurses who having Diploma of Secondary Nursing School had higher percentages of satisfactory knowledge (40\%).

Table (4) shows nurses' knowledge related to infection control where it was found that half percentage of nurses' were having satisfactory knowledge about infection (50\%) followed by universal precaution (35\%). Conversely, only $10 \%$ of them had satisfactory knowledge about cleaning and disinfection. As for total knowledge about infection control, it was satisfactory in $25 \%$ of the studied sample. 
Table (5) shows nurses' knowledge related to invasive procedure. Satisfactory knowledge of nurses was related to suctioning $(65 \%)$ followed by nasogastric tube insertion (55\%). Conversely, only $(15 \%)$ of the nurses had satisfactory knowledge about invasive procedures. Total knowledge about invasive procedures, were satisfactory in $25 \%$ of the studied sample.

Table (6) illustrates the relation between the studied sample practice about infection control and their personal characteristics. It is evident that satisfactory practice were observed among nurses' age 20 years old to 30 years old or more $(35 \%)$, nurses with years of experience from 5 to 10 years or more had $(20 \%)$ respectively. Meanwhile, more than one quarter of nurses with no previous attendance of training courses $(27.5 \%)$, compared to those who had attended such courses $(7.5 \%)$. Nonetheless, as the table shows, none of these differences were statistically significant, $(\mathrm{P}=>0.05)$, except nurses' qualification difference was statistically significant $(\mathrm{P}=>0.05)$.

Table (7) shows the relation between the studied sample practice about invasive procedure and their personal characteristics. It is evident that higher percentages of satisfactory practice were observed among nurses' age 20 years old to 30 years old or more $(10 \%)$, nurses between years of experience from 5 to 10 years or more had higher percentage of practice (12.5\%), nurses who having Diploma of Secondary Nursing School (22.5\%) respectively. Meanwhile, a higher percentage of nurses with no previous attendance of training courses (15\%), compared to those who had attended such courses $(10 \%)$. The table shows that nurses' qualification difference were statistically significant, at $(\mathrm{P}=$ > $0.05)$.

Table (8) shows nurses' practices related to infection control. The studied nurses had satisfactory practice related to hand washing $(30 \%)$ while, a minority of them had satisfactory practice in relation to dealing with gloving (15\%), masking and gowning (10\%). The total practice about universal precautions of the studied sample was satisfactory (30\%).

Table (9) shows practice related to invasive procedures of the studied sample. About half of them had satisfactory practice related to nursing care before insertion of umbilical vessel catheterization (50\%), Followed by suctioning and nursing care after insertion of umbilical vessel catheterization (45\%) but nursing care before intubation of endotracheal tube (40\%). Conversely, only (10\%) of nurses had satisfactory practice about total score insertion of umbilical vessel catheterization. As for the total practice about invasive procedure it was satisfactory $(15 \%)$.

\section{Discussion:}

Infection control practices eliminate the source of infection during invasive procedures and help to protect neonate and health care providers from disease. It is important to bear in mind the responsibility of health care professionals to reduce risks to acquire infection, prevent complication of invasive procedures and to ensure a good quality of care (Potter and Perry, 2004).

The majority of the studied sample were in the age group from $20<30$ years old. Most of them have Diploma of Secondary Nursing School, current job experience from $5<10$ years. Additionally, about $10 \%$ of the studied sample had previous attendance training courses about infection control of invasive procedure. This indicates that a considerable proportion of the nurses in the present study had no long experience, especially in current job. Added to this their qualification, which was mostly at the diploma level. These factors might have their repercussion of the levels of their knowledge and practice. These results are in an agreement with Meltany, (2006) who reported that, the studied sample had higher mean scores of knowledge of nurses who had medium experience and have Secondary Nursing Diplom.

The results have indicated that knowledge was better among older nurses over 20 and less than 30 years compared to those less than 20 years, older than 30 and fewer than 40. This difference was statistically significant. Regarding practice, younger nurses had higher percentage of satisfactory practice compared to the older nurses. This difference was not statistically significant. This may because the older the age of nurses the higher level of knowledge gain. Moreover, as the nurses grows older, nurses are more responsible for administrative and managerial activities, while younger ones have more practical work in direct neonatal care. This finding is in an accordance with the results of the study conducted by Gamal, et al., (2006) who found that, the highest scores of knowledge and practices was found among nurses who were younger, those with the least experience and those have Secondary Nursing Diplom. Hassan and Aboulazm, (2007) also stated that, the highest mean scores of knowledge and practice was found among nurses have Secondary Nursing Diplom

Regarding the relation between nurses' knowledge and practices and their qualifications, the present study findings revealed statistically significant differences either nurses who had Bachelor in Nursing Sciences, Diplom of Technical Nursing Institute and Diplom of Secondary Nursing School (P.0.05). These results are in an agreement with those 
of Abolwafa, (2009) who found that, the total scores of nurses' knowledge that having Diplom of Secondary Nursing School had significantly higher scores than those who having Bachelor in Nursing Sciences. In this respect Ahmed, (2007) reported that, education increases knowledge and practice of nurses having Diplom of Secondary Nursing School. On studying the relation between nurses' knowledge and practice and their experience, the present study findings have revealed statistically significant relation between knowledge and nurses' total and current job experience, with knowledge increasing as the years of experience increased (P. 0.01). Conversely, no statistically significant relation could be shown between years of experience and practice. This may because maturity may play role in gaining and integrating knowledge. Moreover, as the nurses grows older, nurses are more responsible for administrative and managerial activities, while younger ones have more practical work in direct neonatal care. These results are in an agreement with Abolwafa, (2009) reported that, total scores of nurses' knowledge and practice having work experience ranged from 5 to 10 years were higher than those who having worked experience less than 5 years.

In the present study, $10 \%$ only of the nurses had attendance of previous training courses. However, no statistically significant relation could be revealed between attendance of such training courses and their level of knowledge and practice. This finding is in an accordance with the results of the study conducted by Chudleigha, et al., (2005) who found that, the nurse's knowledge and practice who attended training courses about infection control were higher than those who didn't attend. Also it was found by Abolwafa, (2009) that, the total scores of nurses' knowledge and practice who attended training courses about infection control were higher than those who didn't attend.

According to the present study findings, before the training program, nurses' had poor knowledge and practices about both infection control and invasive procedures related to nursing care in neonatal unites. This was indicated by their low scores. The researcher thinks that, this poor baseline knowledge and practices noticed among nurses might be attributed to that, after graduation, nurses abandon reading and neglect updating their professional knowledge. Thus, an important reason for the poor knowledge and practices of nurses lies in the deteriorating status of their knowledge and practices after they graduate, since nurses refrain from trying to improve their knowledge and practices. Another possible reason might be the absence of any resources or programs for continued nursing education that, are essential to upgrade and improve the nurses' knowledge and practices during their care for neonate. These results are supported by Ebrahem, (2009) who stated that, although the majority of the studied nurses had poor knowledge and practices scores before implementation of training program.

\section{Conclusion:}

Based on result of the present study, it can be concluded that, nurses in neonatal units at El-Minia University and General Hospitals were lacking the necessary knowledge and practices related to infection control of invasive procedures.

\section{Recommendations:}

Based on results of the present study, it was recommended that, an application of continuing education programs on regular basis is suggested in order to refresh and update nurse's knowledge, as well as reinforce proper practice related to infection control of invasive procedure. Continuous supervision and evaluation for nurses is needed to determine any defect related to knowledge or practice. Rules and regulation for hospital visitors must be setting and applied. Provision of adequate resources and facilities, (such as protective barriers, sinks, soap, towels, etc.) and equipment related to procedures in health care settings.

\section{References:}

1. Abolwafa N.F., (2009): Assessment of Nurses' Knowledge and Performances Related to Infection Control in Neonatal Units at El Minia City Hospitals, Unpublished Master Thesis in Pediatric Nursing, Faculty of Nursing, Assuit University.

2. Ahmed A.D., (2007): Assessment of Nursing Care Provided for Children Undergoing Haemodialysis, Unpublished Master Thesis, Faculty of Nursing, Alexandria University.

3. Chemaly H.J. (2007): Nosocomial Blood Stream Infections in a Neonatal Intensive Care Unit of a Medical Centre, J Microbiol Immunol Infect; 35(3):168-72.

4. Chudleigha J., Fletcher M. and Gould D., (2005): Infection control in Neonatal Intensive Care Units, J Hosp Infect.; 61(2): 123-9.

5. Ebrahem G.G., (2009): Nurses' Application of Infection Control Precautions in Hemodialysis Unit at El-Mansoura University Children's Hospital. Unpublished Master in Pediatric Nursing, Faculty of Nursing University of Alexandria. 
6. Gamal L.M., Mohamed K.G., Mohamed R.A. and Shawer O. A., (2006): Establishing Standards for Prevention of Nosocomial Infection in the Recovery Rooms and Surgical Ward at El-Minia University Hospital. Doctorate Thesis, Faculty of Nursing, Assiut University.

7. Hassan H.E. and Aboulazm S. F., (2007): Infection Control Education, the New Egyptian Journal of Medicine; 36(1):67-73.

8. Mary E.M., (2005): Pediatric Nursing, Lippincott Company, Philadelphia, Yew York, Baltimore, 3rd ed., 129-130.

9. Meltany L.K., (2006): National Infection Control Epidemiology of Needle Stick and Sharps Injuries in a Tertiary Care Center in Saudi Arabia. Am J Infect Control; 30(2):234-41.

10. Milligan DW, Carruthers PL, Mackley BJ and Ward Platt MP. (2011): 'Nursing Workload in UK Tertiary Neonatal Units' in Archives of Disease in Childhood Published; 5(114):1341 1347.

11. National Institutes of Health (2009): National Guidelines for Infection Control, part 1, Standard Precautions.

12. Patricia A.P. and Anne G.R., (2005): Fundamentals of Nursing, Mosby, London, Sydney, $5^{\text {th }}$ ed., 835-879.

13. Potter P. and Perry A., (2004): Fundamental of Nursing Concepts: Process and Practice, St Louis, Mosby, $5^{\text {th }}$ ed., 835-869.

14. Terese and Marlene (2010): Intravenous Infusion by superficial vein in the Neonate, Journal of Infusion Nursing, 13(2):122-128.

15. Terri K. Kyle T., (2008): Essentials of Pediatric Nursing, Nursing Care of the child with an Infection or Communicable Disorder, Lippincott Williams \& Wilkins, $5^{\text {th }}$ ed., 418-422.

16. White Lois (2007): Basic Nursing Foundations of Skills \& Concepts, Infection Control, Delmar Thomson Learning, Australia and Spain, $6^{\text {th }}$ d., 427-449.

17. Wikimedia Foundation (2006): November http://en.wikipedia.org/wiki/

Neonatal_intensive_care unit 